\title{
Immigrant Volunteering: A Form of Citizenship from Below
}

\author{
Maurizio Ambrosini ${ }^{1} \cdot$ Maurizio Artero $^{1}$ (I)
}

Accepted: 6 January 2022/Published online: 26 January 2022

(C) The Author(s) 2022

\begin{abstract}
Immigrant volunteering is a disputed topic. For some scholars, an important instrument for the social integration of immigrants, while others frame immigrant volunteerism as a regime of 'ethical citizenship' centred around the paradigms of 'civic integration' and 'deservingness'. Our research collected the experiences of hundreds of migrant volunteers in Italy (658 questionnaires plus 89 in-depth interviews) to address three research questions in particular: immigrant volunteers' levels of social inclusion, their reasons for volunteering, and the links between volunteering and other forms of social and political participation. Our findings show that volunteering is more dependent on social integration than on social marginality, represents a way to achieve a higher level of social integration, and can be framed as a way to perform active citizenship and anti-xenophobic claims. In particular, volunteering allows immigrant to present themselves as active subjects, oppose demeaning stereotypes, and express political commitment. Ultimately, this substantiates a form of citizenship 'from below' that re-writes the script of citizenship and enriches it with new ideas of entitlements and belongings.
\end{abstract}

Keywords Immigrant volunteerism - Citizenship - Acts of citizenship · Lived citizenship · Integration

Maurizio Artero

Maurizio.artero@unimi.it

Maurizio Ambrosini

Maurizio.ambrosini@unimi.it

1 Department of Social and Political Sciences, University of Milan, Milan, Italy

\section{Introduction}

In the last years, the relationship between volunteerism and migration has been gaining importance. The mobilization of civil society groups towards migrants, in particular asylum seekers, has had the effect of putting pro-migrant voluntary initiatives on the map (e.g. Fontanari and Borri, 2017; Ambrosini, 2017; Artero, 2019). In this scenario, however, the relationship is generally seen as a one-way solidarity flow emanating from the native, European or North-American population, to migrant people in need. This paper aims to shed light on the opposite case, which often goes unnoticed: the volunteering experience of people with an immigrant background in favour of the wider society. This means to consider immigrants not only in the position of "users" and receivers of services, but also as activators of interventions and protagonists in solidarity movements.

In particular, our study has been driven by three research questions: (1) to find out if people of immigrant origin who take part in volunteering are mainly newly arrived, socially marginal, in difficult economic circumstances, or people who have achieved various levels of social inclusion in the receiving society, in terms of education, employment, citizenship; (2) what internal motivations, social relations or external requests induce immigrants to engage in volunteering, and if and how in particular their participation is connected to aspirations for labour insertion, widening friendship's networks, social acceptance; (3) whether and to what extent volunteering can be framed as a form of active citizenship.

To present and locate our findings in the framework of the international debate, the paper is organized as follows. In the next section, we review the existing research on immigrant volunteering. We emphasize the dispute 
between the proponents of a positive outlook on immigrants' volunteering and the corresponding critical literature, before turning to the notions of acts of citizenship (Isin \& Nielsen, 2008; Isin \& Saward, 2013) and lived citizenship (Lister, 2007). Second, we present our research method; and, third, we discuss findings coming from the empirical materials collected during our research project. This section is divided into three sub-sections, roughly corresponding to the three research questions, which all together support our main argument regarding the manifold significance of immigrant volunteering. Finally, we conclude with implications of our findings and directions for future research.

\section{Immigrant Volunteering, A Disputed Topic}

The volunteering of immigrants is a contested and disputed topic, wherein coexist advocates of at least two different visions: on the one side, the proponents of a positive outlook on immigrants' volunteering, considered as a useful tool and marker of successful integration, and on the other the corresponding critical literature, which regards volunteering as an ally to a neoliberal regime of citizenship. Our theoretical purpose is to illustrate how volunteering can relate to both visions, but represents also the opportunity to 'act' citizenship and to contribute to the rewriting of the dominant script upon which citizenship is usually conceived. To this end, first, we review the literature along the two main lines of thought (i.e. volunteering as integration vs. criticism towards a neoliberal regime of citizenship). To put in contact the literature on immigrant volunteering with the current debate on the forms of citizenship from below, then, we will refer to the notions of acts of citizenship (Isin \& Nielsen, 2008; Isin and Saward, 2013) and lived citizenship (Lister, 2007). These notions, in our view, provide useful theoretical instruments to shed light on the dynamics that we observed at play in our study.

\section{Volunteering as a Useful Tool and Marker of Successful Integration}

Generally speaking, the proponents of a positive outlook on immigrants' volunteering suggest volunteering as one promising path to enhance immigrant integration into host societies, by pointing out the set of benefits that the volunteering experience brings out (e.g. Handy \& Greenspan, 2009; Baert \& Vujic, 2016).

First, this 'positive strand of literature' has underlined the importance of volunteering in building up migrants' social capital (Putnam, 2000) and enhancing skills and language abilities. Handy and Greenspan (2009)'s analysis of the volunteering experiences of immigrants in ethnic congregations in Canada shows that by volunteering immigrants familiarize themselves with the daily-life practicalities of the host country, strengthen their knowledge of the host language, and gain skills and information that help them to get jobs and settle in. Their study highlights the benefits on immigrants' human, social and cultural capital, and also maintains that migrants can build new social connections by joining voluntary activities. Such findings resonate with the result of an analysis on the Italian case by Corrado et al. (2018), which shows how migrants improve their language skills and build up a wider social network through volunteering, and how that benefits their feeling of belonging and social inclusion. After all, the study observes, migrants chose to engage in voluntary work to upscale their social role and hence resist a negative public opinion on them.

Volunteering helps immigrants also by countering prejudices associated with foreigners, oftentimes seen as a threat to native residents (Yuval-Davis et al., 2018), and may even lower discriminations in the job market. As for the first aspect, Vickers (2016) explores the potential of volunteering among international refugees as a tool for opposing negative perceptions. Through a Marxist approach to social capital, he suggests volunteering may build-up 'oppositional social capital' and 'develop wider collective identities" (Vickers, 2016: p. 14). For the latter, instead, in an investigation conducted in the Flemish Region of Belgium, Baert and Vujić (2016) discovered that voluntary experiences positively affect immigrants' chances of obtaining job interviews. Here, while non-volunteering migrants receive fewer positive call-backs and job interviews than non-volunteering natives, the positive callback ratios between volunteering immigrants and volunteering natives are similar.

Lastly, volunteering does not only represent a useful tool for immigrants' social integration; it is also the marker of successful integration. In this sense, Sinha et al. (2011) discovered a positive relationship between the volunteering participation of immigrants in ethnic congregations and the residence-length in the 'host country'. The study highlights how migrant volunteers are people who are already settled on well, and who are in search of a way to actively participate in their new country. Similarly, Greenspan et al. (2018) notice how immigrants in Germany are less likely to partake in voluntary activities than native residents; however, also in this case, people who are already well-established, have acquired national citizenship, and with a good education are most prone to volunteering. 


\section{Immigrant Volunteerism: A Form of 'Ethical Citizenship' or Practice of Citizenship?}

Notwithstanding these studies, over the last decades, we witnessed the emergence of a stream of literature that has harshly criticized immigrants volunteering. Jennifer Wolch's (1990) work on the 'shadow state' has offered a fundamental backdrop to this approach. With this term ('shadow state'), Wolch refers to the process under which voluntary organizations are increasingly involved in welfare provision, taking over responsibilities that have previously been appointed to public institutions. For Wolch, the outsourcing of fundamental parts of welfare activities to voluntary organizations, by filling gaps in the provision of welfare services, serves goals of labour flexibility and supports the weakening of the state and its democratic politics. Following in Wolch's footsteps, Muehlebach's works $(2011 ; 2012)$ on the activities of voluntary groups in Lombardy (Italy) advance the idea that the rise of unremunerated forms of work is closely allied with the thinning of the welfare state. As a corollary to states' externalization, then, Muehlebach points to the emergence of forms of 'ethical citizenship' "producing a 'soulful' citizenry that translates the corporeal stirrings of the heart into publicly useful activity" (Muehlebach, 2012: p. 18). In other words, for Muehlebach, Italian public institutions have invested in producing a sympathetic individual who can deliver, free of charge, those services that the state does not want to provide anymore. Consequently, volunteering is part of a much larger dynamic of growing unemployment rates and precarious labour. It would represent the refuge for marginalized populations (in particular, unemployed youth, immigrants, and retirees), that thereby approximate a form of social belonging in exchange for their free contribution to the society; the toll by which "the worthless of this world produce its greatest wealth" (Muehlebach, 2012: p. 39).

Wolch and Muehlebach's works and their concern about the detrimental effects of volunteering have strongly informed the literature that critiques immigrant volunteerism. For example, from Catalonia (Spain), Codò and Garrido (2014) echo Muehlebach when observing that volunteering is the only way in which immigrants' social participation can be imagined: the economic crisis left the provision of many services for immigrants to voluntary groups, while in turn newcomer immigrants are involved in voluntarism as an alternative to a 'real' paid employment. In this context, the active involvement in voluntary activities is identified as a surrogate of work. Additionally, volunteering has also a strategic value. In a neoliberal state that casts proofs of employment and self-sufficiency as a watershed between the deserving and undeserving immigrants (see Chauvin \& Garcés-Mascareñas, 2014; Guzman
Garcia, 2018), it represents a way to show autonomy and sense of responsibility.

As also argued by Yap et al. (2011) in a study on refugees' unpaid work, thus, volunteers legitimize their activity within the meta-level discourse of 'good citizen'. In line with the neo-liberal philosophy, volunteering represents "a technology of self, a way of transforming the refugee into a 'good citizen'" (Yap et al., 2011: p. 161), justifying a hierarchy of immigrants (e.g. layabout vs active immigrants). In this way, they assert that volunteering also reproduces the status quo concerning dominant discourses about refugees, who deserve to be accepted only when showing the necessary capabilities of initiative and autonomy.

Against this dispute between the proponents of a 'positive' and a 'critical' understanding of immigrant volunteering, our results situate mainly closer to the first. Our findings indicate that volunteering represents a way to strengthen immigrants' social inclusion and social capital, in its individual and collective meaning (Putnam, 2000). At the same time, we differ from other contributions within this literature as we have found that volunteering does not represent merely a useful tool for the individual integration of migrants. Instead, at the core of this contribution is the finding that immigrants' voluntary activities may represent acts expanding the terrain of substantive citizenship, in resonance with ideas of citizenship enshrined in the notions of acts of citizenship (Isin \& Nielsen, 2008) and lived citizenship (Lister, 2007).

The concept of acts of citizenship is part of the growing interest in the conceptualization of citizenship that put emphasis less on legal rules and more on active practices. In particular, this notion focuses on claims and practices enacted by both citizens and non-citizens (e.g. legal immigrants, refugees, undocumented migrants) through which they act and constitute themselves as 'citizens'. It maintains that the notion of citizenship should extend beyond legal membership to encompass various dynamic processes whereby people can constitute themselves as citizens via claims to rights (Isin \& Nielsen, 2008; Isin \& Saward, 2013). Central to this approach to citizenship is what Isin and Saward (2013) call 'activist' citizenship'. While active citizenship concerns formal citizens engaging in political participation based on an existing set of rights, activist citizenship focuses on claims that in various ways challenge existing institutional orders and frameworks of legal citizenship, namely acts of citizenship (ibid.).

This notion has the merit of placing practices at the forefront of conceptualizations of citizenship; however, it confines itself to practices of dissensus' expression within a public domain and discounts other, less spectacular, expressions of opposition. As recognized by a growing scholarship (e.g. Schwiertz \& Schwenken, 2020), instead, 
the notion of acts of citizenship should embrace also 'minor' assertions of citizenship that at first glance have no strong political content (e.g. the humanitarian support that native citizens give to refugees in the host countries). This is because minor assertions (e.g. voluntary activities) can represent 'micropolitical practices' that work to continually challenge the wider macropolitics of government (Artero, 2019).

Additionally, in our view, to extend the meaning of acts of citizenship beyond the public sphere of dissensus, another useful tool is to look at what has been called 'lived citizenship' (Lister, 2007), namely how people negotiate rights and responsibilities, belonging and participation, and understand and feel their citizenship. Drawing from observations on different mundane practices, such the care practices of African American women, Lister (2007) argues that private practices like domestic care may function as forms of lived and participatory citizenship. The resulting concept of citizenship embraces, on the one side, practices that bound a person within a social system, and, on the other, more explicit actions in favour of the citizenry; a form of 'citizenship-from-below' that is not enacted only by partaking in traditional political militancy but also through 'mundane' acts of citizenship.

The acts hereby presented acts are significant since they re-write the script of citizenship and enrich it with new ideas of entitlements and belongings.

\section{Methodology}

Before proceeding to the research findings, we need to set out some specifications concerning methodology and data collection.

This study investigates the volunteering experience of people with an immigrant background in a broad sense. Therefore, the sample includes also second-generation immigrants and naturalized citizens. Among them, we included volunteers who conduct voluntary work both in well-established voluntary associations and in more informal volunteering (e.g. spontaneous groups relatively unstructured); in addition, we selected volunteers who are more dedicated as well as those who chose to give their time occasionally (following a trend of 'post-modern volunteering'; see Ambrosini, 2016).

Against this backdrop, we followed two additional selection criteria. Rather than investigating volunteering within ethnic associations, a well-documented phenomenon, we privileged the experiences of immigrants within voluntary 'national associations and groups', that is, voluntary groups created and mainly composed by native citizens. Even when collecting the experiences of those immigrants engaged in ethnic organizations, however, we favoured the collection of interviews with immigrants volunteering in groups whose activity focus on the wider citizenry. Equally, the data collection sidelined the volunteering of asylum-seekers because recent norms in Italy have made this form of volunteering almost compulsory, which arguably limits its voluntary nature (see Corrado et al., 2018).

The research was carried out in 2019 with the collaboration of Italy's Volunteer Support Centres (CSV) officials. For our study, we used a combination of qualitative and quantitative methods; it is a mixed-methods approach consisting mainly of in-depth interviews and an extensive survey. To this end, a questionnaire (in printed and electronic form) was designed and deployed to gather quantitative information about volunteers' sociodemographic and economic characteristics, their volunteer participation, the 'field of activity' of their engagement, the motivations guiding them to volunteering, their assessment of experience, and any possible critical aspect. In total, 658 volunteers replied anonymously to our questionnaires. We used these data in the first of the three empirical sections to examine the socio-demographic profile of the volunteers and create a profile of a typical volunteer. We joined the questionnaire with 89 in-depth interviews conducted following a semi-structured interview guideline: it focused on dimensions such as their participation, their choice to volunteer, their relationship with the beneficiaries, the outcome of this experience, how the immigrant background affects volunteering. In-depth interviews represent the main method of enquiry for this study, and shape, especially the last two empirical sections. The interviews were conducted individually in Italian by a research team that recorded and transcribed the dialogues. Finally, interviews were analysed by the authors. In this phase, all participants' names have been anonymized to maintain confidentiality.

\section{Who are the Volunteers? The Profile of Our Participants}

Using the data from the questionnaire, it is possible to explore the socio-demographic profile of the volunteers. The sample consisted of men and women, rather equally distributed, with a prevalence of respondents between 20 and 50 years of age (average age of 37 years), and with a relatively diverse 'geographical background' (participants' origins trackback to 80 countries).

Interestingly, our data confirm those studies that point out how immigrants undertaking voluntary activity are often highly educated (e.g. Greenspan et al., 2018): $27 \%$ are university-graduated, while $37 \%$ of participants have a high-school certificate. Compared to the overall immigrant population in Italy (wherein university and high-school 
graduates represent respectively $11 \%$ and $38 \%$ of immigrants), volunteers in our sample have a higher level of education.

Our data also show a positive relationship between the length of stay in the host country and membership in voluntary groups. Of course, recent immigrant volunteers are not lacking; however, our participants have over 15 years of migration experience on average, and five to six years of volunteering experience.

Overall, immigrant volunteers seem to come prevalently from that immigrant population who has already integrated' in Italy. As illustrated by other studies (e.g. Greenspan et al., 2018; Handy \& Greenspan, 2009), immigrants' length of residence and employment status increase volunteering rates. These works suggest that "the longer an immigrant is in the host country, the more likely he or she is to adopt the prevalent culture of volunteering" (Sinha et al., 2011: p. 36). In our case, about 63 per cent of the participants live in Italy for ten or more years, comprising the five per cent of the volunteers that are secondgeneration immigrants, that is, young adults (their age on average is 23) who are born and raised in Italy. Additionally, they generally hold a secure legal status: 40 per cent of the participants are naturalized citizens, 11 per cent are in the process of naturalization, 23 per cent have a longterm residence permit. According to different estimates, less than one per cent are undocumented, compared to the ten per cent of the overall immigrant population in Italy. Furthermore, 63 per cent of the participants are active in the job market (either casual, part-time or full-time employees) compared to the 37 per cent of those who are either students, retirees, housewives/husbands, or unemployed. In this regard, migrant volunteers often explain that they have decided to commit themselves to volunteer after having secured a job and a home.

Hence, if we want to draw an identikit of the typical volunteer in our sample, we may say that s/he is a longterm immigrant or even a naturalized Italian citizen, is incorporated in the social fabric, and has a good educational level. As such, the idea that particularly "passive" and "dependent" migrants are marshalled into volunteering (Muehlebach, 2012) is not reflected in the profile of our participants.

After having outlined the general profile of our immigrant volunteers, in the next part, we zoom in on the reasons and outcomes following their decision to engage in voluntary activities. To this end, we draw the following findings mainly upon the analysis of the 89 in-depth interviews conducted on an individual basis.

\section{Immigrant Volunteering and its Manifold Strategic Significance}

For some critics (e.g. Muehlebach, 2012; Codò \& Garrido, 2014), volunteering is a true regime of 'ethical citizenship' that demands individuals to put their skills and efforts to 'work', with the twofold aim of activating dispensable subjects at the margin of the job market ('weak' immigrants among them) and allowing the state to withdraw from welfare provisioning. In this reading, volunteering is a form of sacrifice and obligation: their adherents (the volunteers) should be animated by selfless, interpersonal giving and ethical urges (Muehlebach, 2012).

As compelling as this reading is, we found that our participants' motivations to volunteer are indeed complex and multiple; they associate the will to spend time and energy on praiseworthy missions with the longing for engaging in pleasing and rewarding activities (Ascoli \& Pavolini, 2017). In particular, immigrants' volunteering is rooted in a desire for social connections, access to the labour market, public recognition and insight into the culture of their host country (see also Handy \& Greenspan, 2009).

In this sense, one of the often-reported motivations to volunteer is indeed the desire to make new friends, not unlike Italian volunteers (Degli Antoni, 2009). In the common context of limited relational networks, immigrants see partaking in associations as a way to improve their relationships in the local community and broaden their bridging social capital with native residents. Following Putnam's (2000) conceptualization, many voluntary associations are sites of building "bridging" social capital. Indeed, the motivation to make new friends draws people into 'national' associations and groups as well as in 'ethnic' organizations; as they told us, indeed, their activities are 'outward-looking' and provide bridging opportunities. In the following excerpt, Marina describes the outcome of such decision in terms of local relational network:

"By volunteering, I met many people and the city of Parma is now more familiar to me. I've befriended some of my fellow-volunteers at the association, with whom I spent my free time" (Marina, 58-year-old, Ukraine).

For Putnam (2000), social capital mostly represents the bonds of mutual trust and reciprocity that hold individuals together and make people cooperate. Yet, social capital is an elastic term and also refers to individuals' social ties and their ability to negotiate access to social and material resources (Portes, 1998). Several interviewees stated that volunteering represents a great opportunity to build social capital to find a job. Therefore, the idea that voluntary work 
is free from utilitarian aims (Muehlebach, 2012) is not generally supported by our findings. By forging connections and social capital, indeed, immigrants can try to gain access to the job market through volunteering (Baert \& Vujic, 2016):

"I was already looking at opportunities to work as a cultural mediator, so I was trying to detect all the associations where I could have worked in my hometown. Thanks to my voluntary work, though, I had the chance to connect with many of these associations, and finally, I found also a job" (Nura, 28, Morocco).

The words of Nura point to the strategic significance social ties established by volunteering may have for one's career; but the interviewees also identified the benefits of volunteering to enter into the labour market in developing substantive knowledge and skills, first of all Italian language, that is human capital.

Among the interviewees, some immigrants gained or improved hard skills that proved to be crucial for their job activities. One of them is Majdi, a volunteer from Tunisia, who said volunteering improved his organizational skills, or Ahmed, who learnt how to use more efficiently standard office software. In this respect, training courses provided by the associations are relevant resources. This is the case of Blaise, a male volunteer from Burkina Faso:

"Through my voluntary work, I learned a lot. I have attended several courses through the years, in particular on fundraising and financial reporting, that I found useful for my job activity too" (Blaise, 46, Burkina Faso).

As already observed, immigrant volunteers are often well-integrated in socio-economic terms and enjoy a full personal life. However, some recent and even long-time migrants reported beginning voluntary work from a lack of other options. In these cases, the motivation to volunteer in order to enter the labour market and make new social connections is understandably more pronounced; over time, anyway, many come to appreciate non-utilitarian benefits. In particular, it emerged that volunteering allows learning other skills, more related to understanding how the new country 'works'. In the words of the interviewees, for example, associations guaranteed the development of useful intercultural skills for learning which behaviours to use in specific situations and how to relate to the native-born population. These findings support Handy and Greenspan (2009) when saying that volunteering enhances not only the individual's human capital but also the ability to understand the written and unwritten mores of a society, namely cultural capital:
"Having conversations with other volunteers allowed me to understand better the context, the Italians. [...] In this sense, it helped me to familiarise myself with the culture. I think one cannot live in a country without knowing what is happening, its culture, how people think" (Georgie, 31, Cameroun).

At the same time, this dynamic of 'understanding' does not run only in 'one direction'. As we will see in detail later, joining an association offered a sort of public recognition for many. We do not read this public recognition in negative terms, as it happens in Muehlbach (2011; 2012): the unremunerated activity of volunteers can represent a means for feeling valued and accepted by the mainstream society; at the same time, it is an instrument for exercising skills and attitudes difficult to express somewhere else. Opportunities for exercising leadership and professional skills in the labour market are, indeed, frequently barred to immigrants (Ambrosini, 2018; Fellini \& Guetto, 2019); in this regard, by volunteering, some have been able to redeem themselves from these limitations. A prime example comes from Shirin, a Bangladeshi woman volunteering in an Italian association. She explains how her encounter with this association allowed her to loosen up her role of wife and mother of three. In this way, not only she has become a central pillar of the organization, developing friendly relations with Italian volunteers, but also an example to other Bangladeshi women: Shirin serves as a linguistic mediator between her compatriots and local services, urges them to follow her example by volunteering, and represents a well-recognized figure in her town.

"Before [volunteering] I was a nobody here. Now when I go out to the public market or the school many people say hi, they come to talk to me [...] to the point that my daughter is jealous; last time, she told me she doesn't want to go with me anymore" (Shirin, 36, Bangladesh).

Shirin's example is certainly piercing. It shows how by volunteering Shirin obtained the public recognition (within both her ethnic community and fellow villagers) hardly granted to a woman in her circumstance. However, also our male participants offered further examples of how voluntary work can be a source of social recognition. The next words are from Maurice, who came from Cameroun to Italy in 1994, and during this time has animated different groups, graduated in Political Sciences, and established his own association:

"During these many years, I think that the major shift is that I started out as a 'victim' but became a 'protagonist'. I said victim because when I arrived here all my expectations fell, so I was feeling a victim. 
But, through the education and my voluntary works, I'm now a 'protagonist'" (Maurice, 49, Cameroun).

These last two interviews, furthermore, elucidate two additional elements. First, while volunteering to catch up with natives regarding human and social capital, participants gain confidence and self-esteem. As Maurice and Shirin point out, thus, the public recognition, along with the assumption of the role of benefactor or leader, transforms immigrant volunteers' self-perception and makes them feel valued (see also, Born et al., 2015; Ambrosini, 2016). Ultimately, these interviews tell us that we cannot reduce volunteering only to a top-down strategy to align a dispensable immigrant population with neoliberal aims and the current status quo; instead, it can also be strategic for immigrants in different ways.

\section{Exploring Immigrant Volunteering as Acts of Citizenship}

As we showed, the concept of acts of citizenship focuses on how both legal citizens and non-legal-citizens constitute themselves as citizens through protests and political mobilizations. Through the concept of lived citizenship (Lister, 2007), we then expand the terrain of acts of citizenship to embrace also more mundane and less politicallycharged practices through which immigrants create a new script in which people with an immigrant background act in effect as citizens and resist demeaning representations of immigrants. As we will see, this comes about in three ways: as construction of active subject; as opposition to demeaning stereotypes; and as a more traditional expression of political commitment.

\section{As Construction of Active Subject}

For a long time, migrant people and even citizens who belong to minorities have been labelled as a threat, economic burden, or as victims (Anderson, 2008; Musarò \& Parmiggiani, 2018). In newsmaking, they are often represented in a passive role (unless they are agents of negative actions, the circumstance that turns them into evil figures) and thus rarely perceived as agents and actors (Bruno \& Peruzzi, 2020). Against this backdrop, as volunteers, they can instead occupy an active position, helping others:

"The most important thing about being a volunteer? Well, I guess is that now I feel useful" (Dolores, 57, Ecuador).

"There are many foreigners that passively receive help. [...] As a volunteer, I earned a position. [...] When I entered, they asked me to guard or clean, the most trivial tasks. But now, I'm part of the Board of this association and I'm the bookkeeper" (Mamadou, 54, Senegal).

As Mamadou's words highlight, indeed, by volunteering immigrants can assume an active role and even attain leading roles within the local community, vis-à-vis other immigrants and the wider community as well. Such aspect is further advanced in the next excerpt from an interview with Melchior, a Burundian man who has extended volunteering experiences with both a formal Italian association and a more informal Burundian group in Italy:

"I'm also the leader of a Burundian group that I founded when a friend here, a fellow countryman, lost his mother and had no money for the funeral. [..]

For this reason, I became the leader of the Burundian community here, by creating a sort of Solidarity Fund by which we help each other" (Melchior, 65, Burundi).

Critics of immigrant volunteering have observed that the alignment of the immigrants with the ideal of the active subject can have detrimental implications. In so doing, indeed, migrants risk strengthening the discourses that frame citizenship as something to be earned by asserting "deservingness" (see Yap et al., 2011; Muehlebach, 2012). Also in our interviews, this aspect emerges. As Andrei in the next excerpt, immigrant volunteers often reveal the acceptance of this script by representing themselves as hard-working and eager to contribute to society:

"I'm truly touched by what I'm doing, because I put myself into it, all my efforts, and this to show to the Italians that I'm here to integrate. I wanted to prove to the Italian people that I really and sincerely want to integrate" (Andrei, 52, Moldova).

However, while following the dominant script legitimizes a discourse of deservingness (Guzman Garcia, 2018), volunteering achieves the primary result of giving immigrants a resource to resist dominant constructions of immigrants as lazy and as outsiders that also circulate in Italy (Musarò \& Parmiggiani, 2018). Furthermore, as we will see, this construction of volunteering goes hand-inhand with the construction of volunteering as an expression of political commitment. Indeed, both constructions are ways in which people break down prejudices. Additionally, this is not in itself an act of political citizenship but constitutes a resource for it: the self and others' perception of migrants as active subjects often constitutes a prerequisite for being heard in the political arena. 


\section{As Opposition to Demeaning Stereotypes}

In Italy, the media discourse on migration revolves around the well-established frames of migrants as invaders, migrants as criminals, and migrants as passive and victimized subjects (Musarò \& Parmiggiani, 2018). These frames are reinforced and simultaneously fed by the (mis)representation of migrants in the population. Many statistics and analyses concur on the negative perception of immigrants and diversity in the Italian population. For example, in a comparative study of 27 countries, it was found that just under half of Italians oppose the idea of a more diverse country, the second-highest proportion after Greece, and well above the median level (Pew Research Centre 2019).

Many interviewees are animated precisely by the will to reverse these negative perceptions of immigrants and obtain a better social image.

"My interest has always been to showcase to Italians that everyone, even those who barely speak Italian, has a culture and a language, which are sophisticated and full of grace and poetry; a heritage not to be dismissed nor neglected" (Viola, 79, USA).

The fight against a detrimental xenophobic discourse is running across several volunteers' accounts. In particular, the youngest segment of our interviewees emphasized this 'fight'. Indeed, young volunteers, often 'second-generation' immigrants who are part of an ostracized minority like Muslims in Italy, share the desire to challenge the diffuse negative perceptions about immigrants via minor yet significant acts. For example, for Saida, the active defence of her religious identity against stigmatization is carried out also by volunteering with a visible Muslim attribute like her headscarf:

"I'm Muslim and woman, and unfortunately now Islam is targeted by the media as reactionary. [...] I volunteer with my headscarf also to defend my religion, to tell, look I'm here, I'm Muslim, I've my headscarf but I'm volunteering. I'm here to tell you that Islam is not oppressive to women, that Muslims want to help people out" (Saida, 27, Morocco).

To do so, volunteers join associations that collaborate, form networks, implement new activities aiming at celebrating foreign cultures. This is the case, for example, of Tatyana and Penelope's associations. Tatyana founded an association of Russian-speaking residents (mostly women working as domestic caregivers) in Naples to promote Eastern European, Russian-speaking women's tradition and culture. To this end, Tatyana organizes festivals and performances illustrating the rich culture of their homeland. Penelope, instead, is a Colombian woman that decided to volunteer in a pro-migrant association. Speaking about her story, she told us:

"I volunteer in an association made up of immigrants from different countries and Italians as well. We carry out activities promoting the values of hospitality and integration. Together we organize festivals, exhibitions etc. In particular, I brought 'collective art' actions into the streets of my hometown" (Penelope, 48, Colombia).

At the core of these activities often seems to lie the refusal towards constructions of citizenry based on the idea that the essence of belonging to a place comes from the fact of 'being here before you' (Geschiere, 2009). Indeed, participants put forward an idea of citizenship regardless of the legal status of citizenship and based on a form of lived citizenship. This idea is also explicated by Mina, secondgeneration with Egyptian origins, who openly contrasts the formal citizenship with another form of citizenship-frombelow, namely civil citizenship:

"I don't believe in the 'formal citizenship'; I believe in 'civil citizenship'. This means you're a citizen if you take part in your society, if you actively operate within it" (Mina, 33, Egypt).

This last interview indicates that the activities aiming at celebrating the immigrant background can both represent the rejection of the many negative representations of immigrants and imply and prefigure the claim for a more radical cultural change. Consequently, volunteering functions as a form of 'resistance bridge' between the personal and the political.

\section{As Expression of Political Engagement}

Volunteering does not only represent an active form of participation with far-reaching benefits. As we have seen for the activities aiming at celebrating the immigrant background, in several cases, immigrants' voluntary work aims more explicitly at pursuing social change. As emerged in many interviews, additionally, volunteering is not in competition with, but even feeds, more explicit forms of political participation. Indeed, in some cases, in parallel with their voluntary activities, volunteers engage also in traditional forms of political militancy, such as organizing political rallies. In this sense, we came across several immigrants who started volunteering in favour of fellow immigrants and ended up conducting anti-discrimination activities. Some immigrants' accounts show that dynamics wherein the voluntary activity initiated for personal interests progressed to forms of advocacy work. In effect, associative practices remain a crucial element for what Vickers (2016) calls 'oppositional social capital'. In this 
regard, the next words from Auguste, a Senegalese man, signal how even a small associative group, consisting of immigrants from the same town, can progress towards forms of engagement moving beyond initial 'bounds'.

"[The association] was born at the end of the ' $90 \mathrm{~s}$ from a group of Senegalese who emigrated to Milan who came from the same area. From there, a series of reflections emerged. [...] Over time, we have widened the scope of our mission: we cooperated with the Senegalese government, we started helping other immigrants from Senegal, even if they are not from the same villages and even if they don't live in Milan, and we started advocating for the wider community" (Auguste, 50, Senegal).

Against this backdrop, participants' construction of active subject co-exists with discourses pointing to volunteering as an expression of political participation. In this discourse, the volunteers position themselves as activists. From this position, they challenge the construction of immigrants as outsiders and the systems which reinforce this construction.

"I've many friends who are activists, and I keep telling them: look, to make politics, to pave the way for a change, you need to change the culture. This is what I'm doing. This also means to make politics" (Sara, 45, Iran).

In our interviews emerged that immigrant volunteering goes also alongside with the participation in consultative bodies and access to what are called 'intermediate political rights' (Zincone \& Ardovino, 2004). Indeed, following their 'activism' in voluntary groups, there are immigrants that have taken an active part in decision-making processes as board members of their voluntary groups or even become part of representative bodies, like the representative body of foreign citizens residing in Italian municipalities. For these participants, volunteering meant the opportunity to participate in collective decisions and acquire civic skills (organizing events, speaking in public meetings), even when lacking formal citizenship status, in line with constructions of lived citizenship (Lister, 2007). As noted earlier, thus, as active subjects immigrants can enjoy public recognition and attain leading roles otherwise denied. Additionally, the exercise of these 'citizenship prerogatives' is a crucial element of the acts of citizenship, under which previously invisible individuals, like migrants, became visible, and non-citizens dismantle assumptions on citizenship as a privilege of legal members (Isin \& Nielsen, 2008): immigrants become citizens by acting as active citizens.

\section{Conclusion. The Social and Political Significance of Immigrants' Volunteering}

Our study on immigrant volunteering in Italy has achieved three main findings, responding to our research questions. About the first question, we have found that volunteering is more dependent on social integration than on social marginality. To be more precise: it is performed by many kinds of people of immigrant origin, but most of them have a secure legal status, often have acquired Italian citizenship, hold employment, have reached high or medium-high levels of education.

For what regards the second research question, we have found that for most participants volunteering, generally speaking, is a way to achieve a higher level of social integration, developing their human and social capital, or to demonstrate the attainment of a good level of social integration. As for native volunteers, self-interest and strategic reasons can support the choice of volunteering in several cases: find employment, improve the knowledge of the language, overcome social isolation and obtain positive public recognition. In any case, these reasons can be summarized under the label of the search for a better inclusion into the receiving society.

The last finding is referred to the third research question: the connection between volunteering and citizenship from below. If citizenship is not only a legal status but a social practice, volunteering can be framed as a way to perform active citizenship.

This point, however, meets some criticisms and should be further elaborated. For some scholars, it is a form of "ethical citizenship", a concession to neoliberal ideologies of the self-reliant citizen, or acceptance of "civic integration" discourses. Within this scholarship, thus, voluntarism represents an instrument for protecting the status quo. We can observe that this strand of literature rests on a rightful critique of the controversial aspects of immigrants' voluntary works legitimizing 'civic integration' discourses (Joppke, 2016). However, the application of such reading to the entire phenomenon of immigrant volunteerism is debatable. This criticism appears to be ideological reductionism: it focuses on extreme cases confirming the theory that the marginal populations bear the burden of replacing public authorities by volunteering to approximate forms of social belonging.

Against this backdrop, instead, our findings bring to broaden the concept of "acts of citizenship", combining it with the idea of "lived citizenship", to include immigrant volunteering. First, as already explained, we contend that in most cases volunteering among immigrants associates with their socio-economic integration, employment status, and acquisition of legal citizenship. Furthermore, provided that, 
by volunteering, often immigrants maintain normative accounts of the 'deserving citizen', in this way they also contest prejudice and stereotypes practically. Doing a service while wearing a veil, or carrying a turban, or being an African young man, represents an open denial of many demeaning representations of immigrants in the eyes of public opinion. The result would be to create a new script in which people with an immigrant background are recognized as citizens. If this brings to divide "bad immigrants" and "good immigrants", it is, in any case, the beginning of a cultural change. In the present political and cultural landscape, deservingness is a tool for breaking xenophobic visions and discourses.

In several cases, the link between volunteering and the political dimension of citizenship is indeed more evident. When immigrant volunteers support newcomers in interacting with public authorities, in accessing public services or in filling an asylum application correctly; when they organize events presenting their cultural heritage to the local population; when they talk in schools and local meetings, in facts they combine the service with a claim for respect and consideration to immigrants and their cultural background. Not rarely, volunteers are also engaged in some forms of political militancy. One activity supports the other one. Skills acquired in volunteering can be useful in the political field, social capital acquired through volunteering can widen the audience for political activities, leadership's capacity can be transferred from one side to the other one.

Ultimately, immigrant volunteering can be framed within the debate on forms of citizenship from below, combining acts of citizenship with the idea of lived citizenship (Lister, 2007; Isin \& Nielsen, 2008; Isin \& Saward, 2013). This citizenship from below is the one enacted not exclusively by partaking in political militancy and protest; in line with works that stress the 'micropolitical' value of volunteerism (e.g. Artero 2019), immigrants re-write the script of citizenship and enrich it with new ideas of entitlements and belongings by partaking in voluntary activities.

Directions for future research encompass a deeper understanding of the attitudes towards volunteering of different kinds of immigrants, being the immigrant population more and more diverse and stratified. For instance, how gender, family status, parental duties affect volunteering. Special attention should be dedicated to volunteering by immigrants experiencing a weaker social and economic position. Another possible development could concern the follow-up of volunteering: if people involved have achieved, after a certain time, the goals they expected, in terms of better employment or social integration. Furthermore, the link between volunteering and political participation could provide another promising ground for future studies: how immigrant volunteers perceive the political dimension of their activity; what types of volunteering trigger an explicit political commitment more easily; if and how immigrant volunteering favours the establishment of networks and alliances with other social and political actors.

Funding This study was funded by the Italian national association of service centres for volunteering (CSV) and conducted with the collaboration of its workers. Its realization was managed by the Centro Studi Medi.

\section{Declarations}

Conflict of interest All authors certify that they have no affiliations with or involvement in any organization or entity with any financial interest or non-financial interest in the subject matter or materials discussed in this manuscript.

Open Access This article is licensed under a Creative Commons Attribution 4.0 International License, which permits use, sharing, adaptation, distribution and reproduction in any medium or format, as long as you give appropriate credit to the original author(s) and the source, provide a link to the Creative Commons licence, and indicate if changes were made. The images or other third party material in this article are included in the article's Creative Commons licence, unless indicated otherwise in a credit line to the material. If material is not included in the article's Creative Commons licence and your intended use is not permitted by statutory regulation or exceeds the permitted use, you will need to obtain permission directly from the copyright holder. To view a copy of this licence, visit http://creativecommons. org/licenses/by/4.0/.

\section{References}

Ambrosini, M. (Ed.). (2016). Volontariato post-moderno: Da Expo Milano 2015 alle nuove forme di impegno sociale. Milano: FrancoAngeli.

Ambrosini, M. (2017). Why irregular migrants arrive and remain: The role of intermediaries. Journal of Ethnic and Migration Studies, 43(11), 1813-1830.

Ambrosini, M. (2018). Irregular Immigration in Southern Europe: Actors, Dynamics and Governance. Palgrave Macmillan

Anderson, B., (2008). 'Illegal Immigrant': Victim or Villain? COMPAS, Working Paper No. 64, University of Oxford (WP08-64).

Artero, M. (2019). Motivations and effects of volunteering for refugees: Spaces of encounter and political influence of the 'new civic engagement' in Milan. Partecipazione e Conflitto, 12(1), 142-167.

Ascoli, U., \& Pavolini, E. (Eds.). (2017). Volontariato e innovazione sociale oggi in Italia. Il Mulino.

Baert, S., \& Vujić, S. (2016). Immigrant volunteering: A way out of labour market discrimination? Economics Letters, 146(9763), 95-98.

Born, M., Marzana, D., Alfieri, S., \& Gavray, C. (2015). "If it helps, I'll carry on": Factors supporting the participation of native and immigrant youth in Belgium and Germany. The Journal of Psychology: Interdisciplinary and Applied, 149(7), 711-736. 
Bruno, M., \& Peruzzi, G. (2020). Per una sociologia delle rappresentazioni mediali delle migrazioni. Un'introduzione. Mondi Migranti, 2(2020), 29-46.

Chauvin, S., \& Garcés-Mascareñas, B. (2014). Becoming less Illegal: Deservingness frames and undocumented migrant incorporation. Sociology Compass, 8(4), 422-432.

Codó, E., \& Garrido, M. R. (2014). Shifting discourses of migrant incorporation at a time of crisis. International Journal of Multilingualism, 11(4), 389-408.

Corrado, A., D’Agostino, E., Musolino, M., Coscarello, C., Buscema, A., \& Vitale, G. (2018). Volunteering Among Immigrants Italy National Report. http:vai-project.eu.

Degli Antoni, G. (2009). Intrinsic vs. extrinsic motivations to volunteer and social capital formation. Kyklos, 62, 359-370.

Fellini, I., \& Guetto, R. (2019). A "U-Shaped" pattern of immigrants' occupational careers? A comparative analysis of Italy, Spain, and France. International Migration Review, 53(1), 26-58.

Fontanari, E., \& Borri, G. (2017). Introduction : civil society on the edge : actions in support and against refugees in Italy and Germany. Mondi migranti, 3, 23-51.

Geschiere, P. (2009). The perils of belonging: autochthony, citizenship, and exclusion in Africa and Europe. University of Chicago Press.

Greenspan, I., Walk, M., \& Handy, F. (2018). Immigrant integration through volunteering: The importance of contextual factors. Victorian Literature and Culture, 47(4), 803-825.

Guzman Garcia, M. (2018). Spiritual citizenship: Immigrant religious participation and the management of deportability. International Migration Review, 52(2), 404-429.

Handy, F., \& Greenspan, I. (2009). Immigrant volunteering. Nonprofit and Voluntary Sector Quarterly, 38(6), 956-982.

Isin, E. F., \& Saward, M. (Eds.). (2013). Enacting European Citizenship. Cambridge University Press.

Isin, Engin F. \& Nielsen, G. (2008). Acts of Citizenship. In European Journal of Migration and Law (Vol. 10, Issue 4).

Joppke, C. G. (2016). After Multiculturalism: Neo-Assimilationist Policies in Europe?. In: Ambrosini, M. (ed.) Europe:No Migrant's Land?. ISPI Report (pp. 69-87).

Lister, R. (2007). Inclusive citizenship: Realizing the potential. Citizenship Studies, 11(1), 49-61.
Muehlebach, A. (2011). On affective labor in Post-Fordist Italy. Cultural Anthropology, 26(1), 59-82.

Muehlebach, A. (2012). The moral neoliberal: Welfare and citizenship in Italy. University of Chicago Press.

Musarò, P., \& Parmiggiani, P. (2018). Taxi o ambulanze del mare? Problemi Dell'informazione, 43(1), 87-114.

Pew Research Center (2019). A Changing World: Global Views on Diversity, Gender Equality, Family Life and the Importance of Religion. Retrieved from: https://www.pewresearch.org/global/ wp-content/uploads/sites/2/2019/04/Pew-Research-Center_Glo bal-Views-of-Cultural-Change_2019-04-22.pdf.

Portes, A. (1998). Social capital: Its origins and applications in modern sociology. Annual Review of Sociology, 24, 1-24.

Putnam, R. D. (2000). Bowling alone: The collapse and revival of American community. Simon and Schuster.

Schwiertz, H., \& Schwenken, H. (2020). Introduction: Inclusive solidarity and citizenship along migratory routes in Europe and the Americas. Citizenship Studies, 24(4), 405-423.

Sinha, J. W., Greenspan, I., \& Handy, F. (2011). Volunteering and civic participation among immigrant members of ethnic congregations. Journal of Civil Society, 7(1), 23-40.

Vickers, T. (2016). Opportunities and limitations for collective resistance arising from volunteering by asylum seekers and refugees in Northern England. Critical Sociology, 42(3), 437-454.

Wolch, J. R. (1990). The shadow state: Government and voluntary sector in transition. The Foundation Centre.

Yap, S. Y., Byrne, A., \& Davidson, S. (2011). From refugee to good citizen: A discourse analysis of volunteering. Journal of Refugee Studies, 24(1), 157-170.

Yuval-Davis, N., Wemyss, G., \& Cassidy, K. (2018). Everyday bordering, belonging and the reorientation of British immigration legislation. Sociology, 52(2), 228-244.

Zincone, G., \& Ardovino, S. (2004). I diritti elettorali dei migranti nello spazio politico e giuridico europeo. Istituzioni Del Federalismo: Rivista Di Studi Giuridici e Politici, 5, 741-762.

Publisher's Note Springer Nature remains neutral with regard to jurisdictional claims in published maps and institutional affiliations. 